\title{
Effects of a Class-Based School Violence Prevention Program for Elementary School Students
}

\author{
Soo Youn Lim', Na Ri Kang ${ }^{1}$, and Young Sook Kwack ${ }^{2}$ \\ ${ }^{1}$ Department of Psychiatry, Jeju National University Hospital, Jeju, Korea \\ ${ }^{2}$ Department of Psychiatry, Jeju National University School of Medicine, Jeju, Korea
}

\begin{abstract}
Objectives: This study was conducted to investigate the effectiveness of a class-based school violence prevention program for elementary school student.

Methods: 29 students were assigned to the school violence prevention program of 8 sessions, 28 students have been assigned to the control group. We assessed participants at baseline and post-intervention, through their self-report questionnaires such as Children's Depression Inventory (CDI), Strengths and Difficulties Questionnaire and school violence experience, awareness about school violence, and coping ability to school violence. We compared the baseline and post-intervention result of each group and compared the posttest scores between the intervention group and the control group.

Results: Comparing the intervention group and the control group, the post-intervention CDI total score and the awareness about school violence showed significant improvement in the intervention group. When compared according to gender, male students' perception of school violence was improved, and female students showed significant differences in CDI scores.

Conclusion: The CDI total scores and the perception of school violence were improved in the intervention group compared to the control group. And there are differential pattern of intervention effects according to gender. These findings have important implications to develop effective violence prevention programs.
\end{abstract}

Key Words: School violence prevention program; Elementary school.

Received: August 22, 2017 / Revision: December 6, 2017 / Accepted: January 4, 2018

Address for correspondence: Na Ri Kang, Department of Psychiatry, Jeju National University Hospital, Aran 13-gil 15, Jeju 63241, Korea

Tel: +82-64-717-1850, Fax: +82-64-717-1849, E-mail: ilnaree@hanmail.net

Address for correspondence: Young Sook Kwack, Department of Psychiatry, Jeju National University School of Medicine, 15 Aran 13-gil, Jeju 63241, Korea

Tel: +82-64-717-1850, Fax: +82-64-717-1849, E-mail: yskcpy@jejunu.ac.kr

\section{INTRODUCTION}

According to the results of the 1st school violence status survey of 2016 conducted by the Ministry of Education, school violence has shown a consistent decline, yet the number of elementary students who have experienced school violence has increased. Most students who were victims of school violence were elementary students at $2.2 \%$ followed by middle school students at $0.5 \%$ and high school students at $0.3 \%$. The victim response rate among elementary school students had increase by $0.1 \%$ p compared to the year prior while there was a $0.2 \%$ p and $0.1 \%$ p decrease for middle school and high school students, respectively, showing that school violence is becoming concentrated in the younger age group. ${ }^{1)}$

Students who are victims of school violence experience de-

This is an Open Access article distributed under the terms of the Creative Commons Attribution Non-Commercial License (http://creativecommons.org/licenses/by-nc/4.0) which permits unrestricted non-commercial use, distribution, and reproduction in any medium, provided the original work is properly cited. pression, chronic school refusal, lower grades, lose educational opportunities from dropping out of school, and have difficulty forming stable peer relationships. ${ }^{2)}$ Further, the experience of continuous school violence across elementary, middle, and high school is known to have a negative effect on physical, socioemotional, and cognitive development compared to a non-school violence group. ${ }^{3)}$

The "Zero Program" that was enforced since 2003 in Norway consists of $3-5$ groups of teachers, parents, and students for each school. A specialist from the outside takes part in these groups to form a specialized network and provide continuous help and support. ${ }^{4}$ ) The Kiva Koulu Program in Finland was developed at the school level aiming to prevent bullying among students. The program involves continuous individual and group discussions to reach detailed solutions to problems through debates, teamwork projects, roleplay activities, and watching bullying videos to help victim students through the active participation of their peers. ${ }^{5)}$ In a meta-analysis on studies examining the effects of school vi- 
olence prevention programs based on 44 classes, while a class-based approach for school violence prevention had decreased aggressive behaviors, ${ }^{6}$ the meta-analysis on the effects of a randomized control test on 28 class-based school violence prevention programs revealed no difference in intervention effects according to the program's structure, participants, or method of approach.7) Hence, there is need for research on the participants, gender, and method of approach for a universal prevention program for primary prevention.

In Korea, a school violence prevention program conducted for 10 sessions with one 4th-grade class in elementary school had a positive effect on reducing aggression compared to a control group, ${ }^{8)}$ and a school violence prevention program conducted for 10 sessions with a 6th-grade class in elementary school improved the participants' self-acceptance and had a positive effect on their attitude toward school violence compared to a control group." Further, the "Eoullim Program," a school violence prevention program developed by the Ministry of Education in Korea in 2013, attempted to cultivate psychosocial competence in elementary, middle, and high school students, such as sympathizing with other students, communication, conflict resolution, self-esteem, and controlling emotions, and to foster coping strategies in students against school violence as active defenders. Students attending schools that underwent the Eoullim Program were found to have a lower tolerance for school violence, and there was significant improvement in behaviors that help prevent school violence, empathy, and communication skills. ${ }^{10)}$

Compared to bullying in other countries, the outcast culture in Korea shows the pattern of a group process in which several members of a group participate throughout the class. Therefore, Korean school violence prevention programs will be effective if they focus on class units for all students in a class. ${ }^{11)}$ However, aside from the application of current classbased prevention programs in the process of experimentation, use of school violence prevention programs that are already developed is still insignificant in the actual school field. Therefore, at a time when the issue of school violence is appearing in lower age groups, primary prevention of school violence through a comprehensive school violence prevention program that takes place over several sessions in an elementary class and can change the perception and coping strategies related to school violence may prevent school violence that occurs at a young age and the complications resulting from such violence.

Based on the survey on the human rights of children and adolescents conducted by the National Youth Policy Institute in $2016,16.2 \%$ of male students and $10.3 \%$ of female students had received serious curses or insults, showing that verbal violence occurs mainly among male students; $7.8 \%$ of male students and 3.1\% of female students were victims of physical violence, showing that physical violence also occurs more among male students. However, $4.3 \%$ of male students and $5.1 \%$ of female students experienced outcasting, ${ }^{12)}$ which shows that relational violence such as out casting is more commonly found among female students. In the study by Cho, ${ }^{13)}$ the rate of physical bullying was higher among male adolescents while relational bullying was more common among female adolescents, and female adolescents were more impacted by contact with delinquent peers, family structure, and school factors than were male adolescents. Moreover, in the study by Lee, ${ }^{14)}$ the degree of damage from school violence was significantly higher among male students than female students, but the mental health level of victim students was significantly lower in female students than male students. As the pattern, cause, and impact of school violence differs according to gender, this indicates a need for other genderspecific methods of intervention in terms of preventing student violence. However, there is a lack of research examining the effects of gender-specific prevention programs thus far.

Hence, this study conducted an 8-session class-based school violence prevention program with elementary students. Level of depression, perception of and attitude toward school violence, and coping ability regarding school violence were compared between the group that participated in the program and the group that did not, and the differences in effects were compared according to gender.

\section{METHODS}

\section{Participants and procedure}

In 2013, two 5th-grade elementary school classes were assigned at random, and 29 students in the class in the experimental group participated in a school violence prevention program twice a week for a total of 8 sessions. This program involved two mental health specialists who visited the school to conduct the program in the class with each session lasting 50 minutes. Twenty-eight students in the class in the control group did not take part in another program during the same period.

Before beginning the program, participants filled out a Children's Depression Inventory (CDI), Strengths and Difficulties Questionnaire (SDQ), and self-report questionnaire that included their experience with school violence, perception of school violence, and ability to cope with school violence. Then, the same questionnaires were filled out after the last program session. This study was approved by the Institutional Review Board of the Jeju National University Hospital (JEJUNUH 2017-04-002). All participants were fully informed of the study protocol and provided written statements 
of informed content that were signed by themselves.

\section{Program composition and progress}

This program was based on the long-term program called "Think Again!" which is a 16-session school violence prevention program developed by the Social Mental Health Lab of the Samsung Life Public Welfare Foundation in 2006 and was composed of 8 sessions based on the conditions and characteristics of the research participants and included six stages of implementation, re-establishing values regarding violence, three perspectives regarding violence, understanding conflicts, problem-solving skills, and conclusion. The structure of the entire 8-session school violence prevention program and the detailed content of each session are included in the Supplementary Table 1 in the online-only Data Supplement.

\section{Measures}

\section{Korean version of the Children's Depression Inventory}

This inventory is Kovacs' modification of Beck's Depression Inventory (1967) to fit the age group of children between 7 and 17 years of age, and this study used the Korean version by Cho and Lee. ${ }^{15)}$ This self-reporting evaluation tool was composed of 27 questions in which participants selected one out of three sentences. The internal consistency was 0.88 , and the reliability coefficient was 0.71 . The total score ranged from 0 to 54 points with higher scores indicating severer depression.

\section{Strengths and Difficulties Questionnaire}

This tool is a scale consisting of 25 questions identifying mental health issues in children and adolescents. "Prosocial behaviors" are evaluated to measure strengths, and difficulties are measured on 4 scales of "hyperactivity/inattention," "emotional symptoms," "conduct problems," and "peer relationship problems," enabling measurement of the various symptoms, strengths, and difficulties of children and adolescents. This tool is also used to measure effects before and after intervention. The applicable matters in each question are marked on a 3-point scale. Points are converted from "Not at all" ( 0 points), "Somewhat" (1 point), and "Definitely" ( 2 point), and inverted questions are converted in the opposite direction. The total strengths score is 10 points with higher scores being more favorable, and the total difficulties score is 40 points with lower scores being more favorable. ${ }^{16)}$

\section{Perception of and attitude toward school violence}

This study used the questionnaire that was restructured by the Social Mental Health Lab of the Samsung Life Public Welfare Foundation based on the scale used in the study by
$\mathrm{Kim}^{17)}$ and the attitude scale that was developed to evaluate the Bullying Prevention Program from the Committee for Children to assess the participants' perceptions of and attitudes toward school violence. Consisting of 17 questions, all questions aside from Question 12, 13, and 17 were inversely calculated. Scores were calculated on a 4-point scale with "Strongly disagree" equating to 1 point and "Strongly agree" equating to 4 points and with higher scores indicating that the participant had a more proper perception of and attitude toward school violence. Cronbach's alpha was $0.78{ }^{2)}$

\section{Experience as an aggressor in school violence}

This study used the adapted version of Crick's ${ }^{18)}$ Peer Nomination Instrument: Relational and Overt Aggression by the Social Mental Health Lab of the Samsung Life Public Welfare Foundation consisting of 10 questions that include content regarding physical violence, verbal violence, and emotional violence during the past school semester. Scores were measured on a 4-point scale with "Never" equating to 1 point and "Often" equating to 4 points and with higher scores indicating that the participant had more experience as the aggressor in violence. The range of responses was 0 to 10 for 10 different experiences of infliction, and the internal consistency (Cronbach's alpha) was $0.79 .^{2)}$

\section{Experience as a victim of school violence}

The questions from Crick's ${ }^{18}$ Peer Nomination Instrument: Relational and Overt Aggression were changed into questions that asked about the participant's experience as a victim and included 10 questions on content regarding physical violence, verbal violence, and emotional violence during the past school semester. Scores were measured on a 4-point scale with "Never" equating to 1 point and "Often" equating to 4 points and with higher scores indicating that the participant had more experience as the victim of violence. The range of responses was 0 to 10 for 10 different victim experiences, and the internal consistency (Cronbach's alpha) was $0.85 .{ }^{2)}$

\section{School violence coping skills}

This study used the questions regarding anger management, conflict resolution, and communication skills used by the Committee for Children and in the study by Seo ${ }^{19)}$ and restructured by the Social Mental Health Lab of the Samsung Life Public Welfare Foundation to evaluate the participants' school violence coping skills. Consisting of 17 questions, scores were measured on a 4-point scale with "Very difficult" equating to 1 point and "Not at all difficult" equating to 4 points and with higher scores indicating that the participant was able to effectively cope with situations related to school violence using proper communication and problem resolution 
skills. The internal consistency (Cronbach's alpha) was $0.89 .^{2)}$

\section{Statistical analysis}

The collected data were analyzed using SPSS ver. 18.0 (SPSS Inc., Chicago, IL, USA), and an independent t-test was used to verify whether the two groups were identical so that the experiment and control groups could be compared. A paired t-test was performed to analyze whether there was differences before and after the program. Further, analysis of covariance was used to analyze differences in the pre- and post-test of the experimental and control groups while differences in the pre-test were controlled.

\section{RESULTS}

\section{Comparison of demographic characteristics and pre-test scores}

All participants in the experimental and control groups were in 5th grade of elementary school. Of the 29 total students who participated in the school violence prevention pro- gram, 16 were male, and 13 were female. Of the 28 total students in the control group, 13 were male, and 15 were female.

Upon comparing the pre-test scores of the experiment and control groups before beginning this program, there was no significant difference in scores for other items aside from the total strengths score of the SDQ. There was no significant difference between the experimental and control groups regarding experience as the aggressor $(p=0.276)$ or victim $(p=0.727)$ of school violence during the past school semester (Table 1).

\section{Program effect on the experimental group and comparison by gender}

This study examined changes in the score of youths in the experiment group evaluated through the self-report questionnaire before and after training through the school violence prevention program. The average depression score had decreased from $13.62( \pm 6.88)$ points before the program to $9.03( \pm 7.25)$ points after the program, and the average score for school violence coping abilities in the questionnaire evaluation increased from $51.14( \pm 14.26)$ points in the pre-eval-

Table 1. Baseline score difference between intervention and control groups

\begin{tabular}{|c|c|c|c|}
\hline & Intervention, mean (SD) $(n=29)$ & Control, mean (SD) $(n=28)$ & p-value \\
\hline CDI & $13.62(6.88)$ & $11.29(7.20)$ & 0.238 \\
\hline SDQ_strengths total score & $4.66(1.63)$ & $6.11(1.50)$ & $0.001^{*}$ \\
\hline SDQ_difficulties total score & $12.89(4.85)$ & $11.81(6.70)$ & 0.499 \\
\hline Awareness of school violence scale & $28.96(8.25)$ & $27.85(6.57)$ & 0.597 \\
\hline Offending experience scale & $16.97(5.65)$ & $15.54(4.10)$ & 0.276 \\
\hline Victimization experience scale & $14.28(3.72)$ & $14.68(4.85)$ & 0.727 \\
\hline Coping abilities to school violence scale & $51.14(14.26)$ & $52.86(9.14)$ & 0.595 \\
\hline
\end{tabular}

${ }^{*} \mathrm{p}<0.05$. CDI: Child Depression Inventory, SD: standard deviation, SDQ: Strengths and Difficulties Questionnaire

Table 2. Pre- and post-intervention score difference in intervention group

\begin{tabular}{|c|c|c|c|}
\hline & Baseline, mean (SD) & Post-intervention, mean (SD) & p-value \\
\hline CDI & $13.62(6.88)$ & $9.03(7.25)$ & $0.000 *$ \\
\hline SDQ_strengths total score & $4.66(1.63)$ & $4.83(1.49)$ & 0.617 \\
\hline SDQ_difficulties total score & $12.89(4.85)$ & $13.86(5.20)$ & 0.192 \\
\hline Awareness of school violence scale & $28.96(8.25)$ & $30.32(7.08)$ & 0.339 \\
\hline Coping abilities to school violence scale & $51.14(14.26)$ & $57.32(10.79)$ & $0.020^{*}$ \\
\hline
\end{tabular}

${ }^{*} \mathrm{p}<0.05$. CDI: Child Depression Inventory, SD: standard deviation, SDQ: Strengths and Difficulties Questionnaire

Table 3. Pre- and post-intervention score difference in intervention group according to gender

\begin{tabular}{|c|c|c|c|c|c|c|}
\hline & \multicolumn{3}{|c|}{ Male } & \multicolumn{3}{|c|}{ Female } \\
\hline & $\begin{array}{l}\text { Baseline, } \\
\text { mean (SD) }\end{array}$ & $\begin{array}{c}\text { Post-intervention, } \\
\text { mean (SD) }\end{array}$ & p-value & $\begin{array}{l}\text { Baseline, } \\
\text { mean (SD) }\end{array}$ & $\begin{array}{c}\text { Post-intervention, } \\
\text { mean (SD) }\end{array}$ & p-value \\
\hline CDI & $13.81(7.32)$ & $10.31(8.40)$ & $0.032 *$ & $13.38(6.58)$ & $7.46(5.43)$ & $0.000^{*}$ \\
\hline SDQ_strengths total score & $4.13(1.63)$ & $5.00(1.50)$ & 0.063 & $5.31(1.44)$ & $4.62(1.50)$ & 0.145 \\
\hline SDQ_difficulties total score & $13.40(5.93)$ & $13.73(6.61)$ & 0.774 & $12.31(3.35)$ & $14.00(3.14)$ & 0.063 \\
\hline Awareness of school violence scale & $30.93(9.54)$ & $33.07(6.20)$ & 0.257 & $26.00(4.90)$ & $26.20(6.49)$ & 0.931 \\
\hline Coping abilities to school violence scale & $52.60(14.88)$ & $57.40(11.17)$ & 0.282 & $49.46(13.91)$ & $57.23(10.80)$ & $0.006^{*}$ \\
\hline
\end{tabular}

${ }^{*} \mathrm{p}<0.05$. CDI: Child Depression Inventory, SD: standard deviation, SDQ: Strengths and Difficulties Questionnaire 
uation to $57.32( \pm 10.79)$ points in the post-evaluation for the experimental group (Table 2).

Moreover, when the pre- and post-evaluation gender differences were compared for the experimental group, there was a significant decrease in the depression score in the postevaluation for both the male $(\mathrm{p}<0.05)$ and female student groups $\mathrm{p}<0.01)$. In addition, there was a significant increase $\mathrm{p}<0.01)$ in the school violence coping ability evaluation for the female student group from $49.46( \pm 13.91)$ in the pre-evaluation to 57.23 ( \pm 10.80$)$, but there was no significant difference in the male student group (Table 3 ).

\section{Program effect on the experimental and control groups and comparison by gender}

Upon performing an analysis of covariance on each evaluation item between the experimental and control groups, there was a significant improvement in the CDI [sum of square $(S S)=274.876$, mean square $(M S)=274.876, p<0.01]$ and changes in school violence perception ( $\mathrm{SS}=197.128, \mathrm{MS}=197.128$, $\mathrm{p}<0.01)$ for the experimental group compared to the control group (Table 4).

In the analysis of covariance between the experimental and control groups according to gender, there was a signifi- cant improvement in the perception of school violence in the male student group ( $\mathrm{SS}=206.738, \mathrm{MS}=206.738, \mathrm{p}<0.01$ ), and there was a significant difference in the score for the CDI (SS= 584.624, MS $=584.624, \mathrm{p}<0.01)$ in the female student group in the experimental group compared to the control group (Table 5).

\section{DISCUSSION}

Upon comparing the pre- and post-evaluation scores of the experimental group from the school violence prevention program, depression scores decreased, and school violence coping abilities had improved. There was significant improvement in school violence coping abilities in the female student group, but there was no significant difference in the male student group. Upon comparing the experimental and control groups, there was a decrease in depression scores and a significant improvement in the perception of school violence for the experimental group compared to the control group. The male students in the experimental group showed a significant improvement in their perception of school violence compared to the control group, and there was a significant decrease in depression scores for the female students.

Table 4. CDI, SDQ and awareness of school violence, school violence experiences, and coping abilities to school violence scale in intervention group

\begin{tabular}{|c|c|c|c|c|c|c|}
\hline & \multicolumn{2}{|c|}{ Intervention, mean (SD) (n=29) } & \multicolumn{2}{|c|}{ Control, mean (SD) $(\mathrm{n}=28)$} & \multirow{2}{*}{$F$} & \multirow{2}{*}{ p-value } \\
\hline & Baseline & Post-intervention & Baseline & Post-intervention & & \\
\hline$\overline{C D I}$ & $13.62(6.88)$ & $9.03(7.25)$ & $11.29(7.20)$ & $11.54(6.73)$ & 12.571 & $0.001^{*}$ \\
\hline SDQ_strengths total score & $4.66(1.63)$ & $4.83(1.49)$ & $6.11(1.50)$ & $5.65(1.54)$ & 0.453 & 0.504 \\
\hline SDQ_difficulties total score & $12.89(4.85)$ & $13.86(5.20)$ & $11.81(6.70)$ & $11.62(6.79)$ & 0.425 & 0.518 \\
\hline Awareness of school violence scale & $28.96(8.25)$ & $30.32(7.08)$ & $27.85(6.57)$ & $24.69(5.15)$ & 8.614 & $0.005^{*}$ \\
\hline Coping abilities to school violence scale & $51.14(14.26)$ & $57.32(10.79)$ & $52.86(9.14)$ & $57.42(10.86)$ & 0.308 & 0.581 \\
\hline
\end{tabular}

Statistical significance was tested by analysis of covariance adjusted for CDI, SDQ, awareness of school violence scale, coping abilities to school violence scale. ${ }^{*} \mathrm{p}<0.05$. CDI: Child Depression Inventory, F: F-statistic, SD: standard deviation, SDQ: Strengths and Difficulties Questionnaire

Table 5. CDI, SDQ and awareness of school violence, school violence experiences, and coping abilities to school violence scale in intervention group according to gender

\begin{tabular}{|c|c|c|c|c|c|c|c|c|}
\hline & \multicolumn{8}{|c|}{ Intervention (n=29) } \\
\hline & \multicolumn{4}{|c|}{ Male } & \multicolumn{4}{|c|}{ Female } \\
\hline & $\begin{array}{l}\text { Baseline, } \\
\text { mean (SD) }\end{array}$ & $\begin{array}{c}\text { Post-intervention, } \\
\text { mean (SD) }\end{array}$ & $\mathrm{F}$ & $\mathrm{p}$-value & $\begin{array}{l}\text { Baseline, } \\
\text { mean (SD) }\end{array}$ & $\begin{array}{l}\text { Post-intervention, } \\
\text { mean (SD) }\end{array}$ & $\mathrm{F}$ & p-value \\
\hline CDI & $13.81(7.32)$ & $10.31(8.40)$ & 2.623 & 0.121 & $13.38(6.58)$ & $7.46(5.43)$ & 11.819 & $0.002^{*}$ \\
\hline SDQ_strengths total score & $4.13(1.63)$ & $5.00(1.50)$ & 0.453 & 0.504 & $5.31(1.44)$ & $4.62(1.50)$ & 3.870 & 0.060 \\
\hline SDQ_difficulties total score & $13.40(5.93)$ & $13.73(6.61)$ & 0.845 & 0.368 & $12.31(3.35)$ & $14.00(3.14)$ & 6.142 & $0.020^{*}$ \\
\hline $\begin{array}{l}\text { Awareness of school } \\
\text { violence scale }\end{array}$ & $30.93(9.54)$ & $33.07(6.20)$ & 10.711 & $0.004^{*}$ & $26.00(4.90)$ & $26.20(6.49)$ & 1.424 & 0.245 \\
\hline Coping abilities to school & $52.60(14.88)$ & $57.40(11.17)$ & 0.267 & 0.610 & $49.46(13.91)$ & $57.23(10.80)$ & 0.674 & 0.419 \\
\hline
\end{tabular}

violence scale

Statistical significance was tested by analysis of covariance adjusted for CDI, SDQ, awareness of school violence scale, coping abilities to school violence scale. ${ }^{*} \mathrm{p}<0.05$. CDI: Child Depression Inventory, F: F-statistic, SD: standard deviation, SDQ: Strengths and Difficulties Questionnaire 
The results of this study is consistent with previous studies reporting that school violence prevention programs can decrease tolerance regarding school violence and are effective in helping students fix incorrect biases. ${ }^{20)}$ The results of this study are also consistent with the study by Lee, ${ }^{21)}$ which is similar to this study in that a 12 -session program was conducted on 4th-grade elementary school students and a 6-session program was conducted on 5th- and 6th-grade elementary school students and found that students were able to form a correct attitude toward school violence through the school violence prevention program and that the effects were lasting.

This study found a significant improvement in depression scores, but it is difficult to make direct comparisons since previous studies on school violence prevention programs did not typically use a depression scale. However, considering that the Eoullim School Violence Prevention Program, which is being implemented nationally by the Ministry of Education, demonstrates results that a school violence prevention program in itself is effective in psychosocial development and school adjustment, ${ }^{22)}$ the time spent through this study on regularly acknowledging conflicts between peers and finding ways to cope with these conflicts over a set period with students in the same class rather than a 1-time training session may have been an opportunity for these students to experience positive emotions. Considering that school violence often occurs inside the school (71.4\%) rather than outside the school (28.6\%) and that it occurs more often inside the same class, ${ }^{1)}$ it may be that conducting the same school violence prevention program and sharing the same content between students in the same class was helpful.

Changes in the perception of and ability to cope with school violence are important factors in preventing school violence, and, because these social cognitive factors are established through experience with peer relationships at a young age, such as in elementary school, elementary school students may be the primary targets for these prevention programs. However, while this study found improvements in the perception of school violence compared to the control group, there was no significant difference in the school violence coping skills score. As with this study, the results of universal prevention programs that primarily focus on attitude and belief regarding school violence are not yet consistent as some studies have reported small changes in the perception of school violence ${ }^{23,24)}$ while others have seen significant improvements in the participants' attitude regarding nonviolence. ${ }^{25)}$ In other studies, when a prevention program was conducted on elementary school students, students showed significant changes in the social-cognitive domain, and such changes were reported to have a mediating effect preventing increases in violent behaviors. ${ }^{26)}$ In a study recently presented in Korea that analyzed the effects of the Eoullim School Violence Prevention Program, ${ }^{27)}$ the module with the greatest influence on school violence was the empathy module, which was more useful in changing perceptions and attitudes than other participants. Of this module, the greatest indirect effect was observed through the communication $\rightarrow$ empathy $\rightarrow$ school violence perception and coping path. Therefore, there must be additional research on effective approaches to improve school violence perception and coping skills more comprehensively. Going forward, taking an approach that focuses on changes in the social-cognitive domain by improving empathy and communication skills may be helpful in devising a program for primary prevention in the future.

This study found gender differences in the effects of the prevention program. Compared to the control group, there was a significant decrease in the school violence perception domain for the male students and in depression scores for the female students in the experimental group. Previous studies have reported that male students have a weaker standard of judgment regarding aggressive behaviors than do female students, ${ }^{28)}$ and, in terms of gender differences and peer interaction, female students had higher emotional intelligence than male students while male students had higher aggression than did female students. ${ }^{29)}$ Due to these gender differences in interaction methods, the emotional effects of the program, such as depression, may have been more apparent in the female students in this study while the cognitive effects, such as the concept of school violence and perception of aggressive behaviors, may have been more apparent than emotional effects for the male students. However, since the average scores for both the male and female students were not strong indications of depression, it is difficult to guarantee that this improvement in depression score signifies an improvement in feelings of depression. Yet, since this study does indicate that that the school violence prevention program had an incidental effect on emotional issues such as depression, a more large scale study in the future must assess whether a school violence prevention program can help with emotional issues aside from school violence.

Based on the patterns of school violence, male students tend to show more external aggressive behaviors while school violence behaviors among female students are often mediated through relationships, such as spreading a bad rumor or alienating someone, rather than a more direct approach such as aggression. ${ }^{30)}$ In other words, in addition to factors that directly address the concept of school violence and its management, it will be effective to utilize factors that address relationships, empathy, and emotions in consideration 
of the characteristics interaction among female students.

Most current school violence prevention programs that target ordinary students are conducted by separating students by age and year into elementary, middle school, and high school. However, since there were gender differences in the pre- and post-test results through the program, there must be research on whether gender differences truly exist in the program effects. When school violence prevention programs are conducted in the future, it is necessary to consider a program structure based on gender in addition to approaches based on age and school.

This study was conducted on 57 students in two 5th-grade elementary school classes, a sample size that is too small to generalize to the entire 5th-grade student population. Hence, there is need for a largescale school violence prevention program conducted with elementary school students. Further, the program used in this study was based on the 16-session school violence prevention program developed by the Social Mental Health Lab of the Samsung Life Public Welfare Foundation in 2006 and reconstructed into 8 sessions to fit the conditions and characteristics of the participants of this study, and these sessions addressed the perception of school violence and how to manage school violence and conflicts. Because this study was unable to fully address domains that are the cause of school violence and conflict, such as empathy or emotion control, this program may have been insufficient as a primary prevention method for school violence. Going forward, adding sessions related to empathy or emotion control may be helpful.

Despite this, this study holds significance in that it conducted an 8-session school violence prevention program in class units and compared the results between the experimental and control groups and went beyond an analysis of gender differences in the cause and victim effect from previous studies but also explored gender differences in the effects of the prevention program. This can be used to help develop and use more effective school violence prevention programs in the future.

\section{CONCLUSION}

This study has indicated that a class-based school violence prevention program has a positive effect on the emotions and perception of elementary school students and that the program's effects may differ according to gender. Moreover, there must be a largescale study, and a class-based school violence prevention program must be developed for comprehensive improvements in school violence, perception, and management for primary prevention.

\section{Supplementary Materials}

The online-only Data Supplement is available with this article at https://doi.org/10.5765/jkacap.2018.29.2.54.

\section{Acknowledgments}

The main points of this study were presented in a poster at the 2017 Spring Symposium of the Korean NeuroPsychiatric Association.

\section{Conflicts of Interest}

The authors have no financial conflicts of interest.

\section{REFERENCES}

1) Ministry of Education. Results of the first school violence survey in 2016 [cited 2016 Jul 18]. Available from: http://moe.go.kr/boardCnts/view.do?boardID $=294 \&$ boardSeq $=63780 \&$ lev $=0 \&$ searchTy $\mathrm{pe}=$ null\&statusYN=W\&page $=36 \& \mathrm{~s}=$ moe $\& \mathrm{~m}=0503 \&$ opType $=\mathrm{N}$.

2) Noh HL, Kim HT, Yoo SK. A study on the effectiveness of school violence prevention programs. Samsung Life Insurance Foundation Social Health Institute; 2006.

3) Kim HS. An effect of persistent school violence victimization experience on youths' physical, socioemotional, and cognitive development. J Adolesc Welf 2013;15:121-143.

4) Park HJ. Actual conditions and measures of school violence in norway and implications for Korean education. Korea Educational Development Institute;2012.

5) Kim BC. Finland Kiba Kohlu program and implications for korean education. Korea Educational Development Institute;2012.

6) Mytton JA, DiGuiseppi C, Gough DA, Taylor RS, Logan S. Schoolbased violence prevention programs: systematic review of secondary prevention trials. Arch Pediatr Adolesc Med 2002;156:752-762.

7) Park-Higgerson HK, Perumean-Chaney SE, Bartolucci AA, Grimley DM, Singh KP. The evaluation of school-based violence prevention programs: a meta-analysis. J Sch Health 2008;78:465-479. quiz 518-520.

8) Tak AH. The effect ot the school violence prevention program on the reduction of aggression among elementary school 4th graders [dissertation]. Seoul: Hanyang Univ.;2012.

9) Shin HY. The effect of the school violence prevention program on self-acceptance, other-acceptance, attitudes toward school violence [dissertation]. Gwangju: Gwangju National University of Education;2015.

10) Kim JA. 2014 Harmony program operating performance and future plans. Korea Education Development Institute School Violence Prevention Research Support Center Newsletter 2015 vol.02 [cited 2015 Aug]. Available from: http://stopbullying.kedi.re.kr/newsletter/ v1508/2015vol02_newsletter_special01.html.

11) Kwak KJ. Korean Wang-Ta and school violence: characteristics and prevention program. Proceedings of the Korean Psychological Assocoaition Annual Conference;2006 Aug 17-19;Seoul, Korea. Seoul: Korean Psychological Assocoaition;2006. p.134-135.

12) Korea Youth Policy Institute. Survey on human rights of children and youth VI. Korea Youth Policy Institute;2016.

13) Cho YH. Gender differences in prevalence and predictors of school violence. J Adolesc Welf 2013;15:155-179.

14) Lee EH. The effect of the adolescent student's school violence experience on mental health-the mediating effect of resilience. J Korea Acad Industr Coop Soc 2017;18:146-156.

15) Cho SC, Lee YS. Development of the Korean form of the Kovacs' Childeren's Depression Inventory. J Korean Neuropsychiatr Assoc 1990;29:943-956.

16) Goodman R. The Strengths and Difficulties Questionnaire: a re- 
search note. J Child Psychol Psychiatry 1997;38:581-586.

17) Kim HJ. The development of school-violence prevention program and analysis of its effects [dissertation]. Chonnam National Univ.; 2002.

18) Crick NR. Engagement in gender normative versus nonnormative forms of aggression: links to social-psychological adjustment. Dev Psychol 1997;33:610-617.

19) Seo MH. The effect of anger control program for children [dissertation]. Busan: Busan National University of Education;2002.

20) Lee JH. Effect of group program by traditional play on children's attitude to school violence and school satisfaction [dissertation]. Daejeon: Daejeon Univ.;2011.

21) Lee CS. Effects of school violence prevention program on school violence attitude, aggression and self-esteem [dissertation]. Jinju: Gyeongsang National Univ.;2012.

22) Lee CS. The effects of the harmony program for elementary school students on sociality improvement and anger reduction [dissertation]. Daegu: Keimyung Univ.;2017.

23) Farrell AD, Valois RF, Meyer AL. Evaluation of the RIPP-6 violence prevention program at a rural middle school. Am J Health
Educ 2002;33:167-172.

24) Farrell AD, Meyer AL, Sullivan TN, Kung EM. Evaluation of the Responding in Peaceful and Positive Ways (RIPP) seventh grade violence prevention curriculum. J Child Fam Stud 2003;12:101-120.

25) Farrell AD, Valois RF, Meyer AL, Tidwell RP. Impact of the ripp violence prevention program on rural middle school students. J Prim Prev 2003;24:143-167.

26) Ngwe JE, Liu LC, Flay BR, Segawa E, Aban A. Violence prevention among African American adolescent males. Am J Health Behav 2004;28 Suppl 1:S24-S37.

27) Lee JH. Relationship among modules of the national level school violence prevention program-focused on the Eoullim Program. J Educ Res 2016;14:187-212.

28) Hyun JH. Differences in perception of 'peer bullying' by gender. Korean J Jpn Educ 2000;4:133-147.

29) Kim SH. Relationship between peer interaction, emotional intelligence, and aggression [dissertation]. Incheon: Incheon Univ.;2013.

30) Moon YL, Choi JY. A social psychological study on the characteristics and mechanisms of female violence behavior. Seoul: Seoul National University;2006. 